\title{
ASPECTOS PATOLÓGICOS DA INTOXICAÇÃO DE SUÍNOS POR SEMENTES DE Crotalaria spectabilis (Fabaceae) ${ }^{1}$
}

\author{
Adriana Coelho de Souza ${ }^{2}$, Mario Roberto Hatayde ${ }^{3}$ e Gervásio Henrique Bechara ${ }^{4}$
}

\begin{abstract}
Souza A.C., Hatayde M.R. \& Bechara G.H. 1997. [Pathological aspects of poisoning by Crotalaria spectabilis (Fabaceae) seeds in swine.] Aspectos patológicos da intoxicação de suínos por sementes de Crotalaria spectabilis (Fabaceae). Pesquisa Veterinária Brasileira 17(1):1218. Depto Patologia Animal, Faculdade de Ciências Agrárias e Veterinárias, Unesp-Campus de Jaboticabal, Rodovia Carlos Tonanni Km 5, Jaboticabal, SP 14870-000, Brazil.

A feeding experiment was undertaken using 24 weanling pigs, distributed in four treatments, with 6 animals in each group. The animals of group 1, 2, 3 and 4 were fed with rations containing $0.0,0.2,0.4$ and $0.6 \%$ of Crotalaria spectabilis seeds, respectively, during a period of 90 days. Postmorten examination was performed immediately after death in the animals which died during the experiment. The pigs which survived were sacrificed on the last day of the experiment. During the autopsy fragments of liver, kidneys, lungs and stomach were collected for histological examination. The main clinical signs of the intoxication were subcutaneous oedema, affecting particulary the face, limbs and neck, pale ocular and oral mucous membranes, ruffled bristle, emaciation and apathy. Hydropericardium was the most common finding at necropsy, occurring in several intoxicated animals. The major microscopic changes were fibrosis, bile ductulus proliferation and megalocytosis in the liver, bronchopneumonia and chronic bronchitis, renal tubular cell megalocytosis, nephrosis and chronic nephritis, as well as gastritis and gastric ulcerations. The experimental findings showed that rations contaminated with $C$. spectabilis seeds, at the used rate, were toxic to swine.
\end{abstract}

INDEX TERMS.: Poisonous plants, Crotalaria spectabilis, experimental poisoning, swine pathology.

SINOPSE.- Foram utilizados 24 suínos desmamados, distribuídos em quatro tratamentos, com seis animais em cada. Os suínos dos tratamentos $1,2,3$ e 4 receberam, durante 90 dias, ração com respectivamente: $0,0,0,2,0,4$ e $0,6 \%$ de sementes de Crotalaria spectabilis. Os animais que morreram durante o período experimental foram necropsiados logo após a morte. Os sobreviventes foram sacrificados no último dia do experimento. Durante as necropsias, foram colhidos fragmentos do fígado, rim, pulmão e estômago, para realização de exame histopatológico. Os principais sintomas da intoxi-

\footnotetext{
${ }^{1}$ Aceito para publicação em 31 de outubro de 1996. Apoio financeiro: FAPESP e CNPq.

${ }^{2}$ Departamento de Patologia Animal, Faculdade de Ciências Agrárias (FCAV), Unesp-Campus de Jaboticabal, Rodovia Carlos Tonanni Km 5, Jaboticabal, SP 14870-000.

${ }^{3}$ Departamento de Clínica e Cirurgia Veterinária, FCAV, Unesp-Campus de Jaboticabal.

${ }^{4}$ Departamento de Patologia Animal, FCAV, Unesp-Campus de Jaboticabal.
}

cação foram edemas subcutâneos, principalmente nos membros, na face e região do pescoço, mucosas oral e ocular pálidas, cerdas eriçadas, caquexia e apatia. O hidropericárdio foi a lesão macroscópica mais comum, acometendo vários animais que receberam a ração contaminada. As principais lesões microscópicas foram fibrose, proliferação de ductos biliares e megalocitose no fígado, broncopneumonia e bronquite crônicas, megalocitose de células epiteliais tubulares renais, nefrose e nefrite crônica, bem como gastrite e ulceração gástrica. Os resultados destes experimentos indicam que ração contaminada com sementes de $C$. spectabilis, nas proporções utilizadas, foi tóxica para suínos.

TERMOS DE INDEXAÇÃO: Plantas tóxicas, Crotalaria spectabilis, intoxicação experimental, suíno, patologia.

\section{INTRODUÇÃO}

A intoxicação por plantas normalmente causa danos severos aos animais domésticos, acarretando consideráveis perdas econômicas ao país. Dentre essas plantas, Crotalaria spectabilis 
desde há muito tempo é conhecida como tóxica aos animais domésticos, sendo a espécie suína considerada a mais susceptível aos seus efeitos. C. spectabilis é uma leguminosa comumente utilizada como adubação verde em vários países, inclusive no Brasil; devido este fato pode ser encontrada em plantações como milho, soja e sorgo. Nessa cirscunstância, suas sementes podem ser, inadvertidamente colhidas com essas culturas e aparecerem em rações de animais.

$\mathrm{O}$ principal princípio tóxico, encontrado em $C$. spectabilis é o alcalóide pirrolizidínico denominado monocrotalina, a qual foi isolada por Neal et al. (1935), podendo ser detectada em todas as partes da planta (Piercy \& Rusoff 1946) incluindo-se folhas e sementes (Johnson et al. 1985). Segundo Mattocks (1986), a toxicidade dos alcalóides pirrolizidínicos resulta em danos irreversíveis ao fígado. Ocorre gigantismo citoplasmático e nuclear (megalocitose) (Bull 1955, Cheeke \& Shull 1985, Mattocks 1986, Thomson 1990, Jubb et al. 1993). Outras lesões incluem fibrose progressiva, proliferação de ductos biliares (Cheeke \& Shull 1985, Mattocks 1986, Thomson 1990) e veno-oclusão (Cheeke \& Shull 1985, Mattocks 1986). Há diminuição das funções metabólicas hepáticas; os níveis de proteína sérica tornam-se diminuídos, devido à diminuição na síntese protéica (Miranda et al. 1980), levando a ascite e edema (Cheeke \& Garman 1974).

Alguns metabólitos dos alcalóides pirrolizidínicos hepatotóxicos podem causar danos aos pulmões (Mattocks 1972), levando a lesão intersticial e arteriolar pulmonar. Podem ocorrer mortes devido à lesão renal (Jubb et al. 1993); as principais alterações observadas nos rins são lesões tubulares e glomerulonefrite (Hayashi \& Lalich 1967, Carstens \& Allen 1970, McGrath et al. 1975, Figueredo et al. 1987).

Emmel et al. (1935) observaram resultados fatais quando intoxicaram, experimentalmente um grupo de 10 e outro de 5 suínos da raça Poland China com, respectivamente, 0,5 e $2,0 \mathrm{~g}$ de sementes de $C$. spectabilis administradas por via oral, uma vez ao dia. 0 grupo que rebeceu $0,5 \mathrm{~g}$ foi tratado durante 57 dias, e os animais do grupo de $2,0 \mathrm{~g}$ receberam sementes por um período de 9 a 18 dias. As principais lesões macro e microscópicas observadas por estes autores foram anemia severa, acúmulo de líquido nas cavidades abdominal e torácica, equimoses no endocárdio, gastrite, congestão, tumefação turva de todos os orgãos parenquimatosos, músculo cardíaco e musculatura lisa de vísceras, edema e focos de necrose nos linfonodos e orgãos parenquimatosos. Frequentemente, as mortes ocorreram devido a hemorragia gástrica.

Casos agudos e crônicos naturais de intoxicação por $C$. spectabilis têm ocorrido frequentemente em suínos. De acordo com Emmel (1943), nos casos agudos os animais podem sobreviver por 2 semanas. Geralmente, ocorre diminuição do apetite e anemia. Nos casos crônicos, os animais tornam-se improdutivos. Suínos recebendo ração de engorda não ganham peso satisfatoriamente. Os suínos podem morrer devido à intoxicação crônica por $C$. spectabilis 2 a 3 meses após ter cessado o acesso destes animais à planta. A principal lesão macroscópica é cirrose atrófica do fígado. Os linfonodos mesentéricos, geralmente tornam-se pálidos e fibrosos.
Sangster (1972) estudou um caso natural de intoxicação crônica em suínos com sementes de $C$. spectabilis. A concentração exata de sementes na ração não era conhecida, entretanto amostras do milho utilizado na ração revelaram concentração acima de $1,16 \%$ de sementes de $C$. spectabilis por quilograma de milho. A partir deste estudo, concluiu que lesões macroscópicas como fibrose hepática, ascite e ulcerações na região esofágica do estômago são sugestivas de intoxicação por $C$. spectabilis em suínos. As principais lesões microscópicas observadas na intoxicação crônica estavam localizadas no fígado, nos pulmões e rins. Ocorreu aumento de tamanho dos hepatócitos e seus núcleos tornaram-se pálidos e granulares. Observaram-se vários graus de fibrose centrolobular e interlobular hepática. Os pulmões apresentaram fibrose intersticial com espessamento das paredes alveolares e aumento de tamanho das células septais. Também, estavam presentes lesões degenerativas em arteríolas. Urinálises, exames hematológicos, bem como testes bioquímicos séricos para avaliação da função hepática tiveram pouco ou nenhum valor no diagnóstico da toxicidade crônica por crotalária em suínos. As lesões microscópicas persistiram por longo período de tempo após a remoção das sementes da dieta. De acordo com Sangster (1972), o diagnóstico definitivo da intoxicação deve ser determinado pela presença das sementes de $C$. spectabilis na ração, pois as lesões encontradas nessa intoxicação são semelhantes às encontradas em intoxicações causadas por outras plantas que também contêm alcalóides pirrolizidínicos.

Segundo Peckham et al. (1974), em um rebanho de suínos ao qual foi fornecido uma ração contendo milho contaminado com $0,5 \%$ de sementes de $C$. spectabilis, morreram 76 de um total de 150 animais. As primeiras mortes ocorreram 6 semanas após o início do consumo da ração e 3 semanas após a queda de pêlos pretos do corpo dos animais, sendo que esse foi o primeiro sinal clínico observado. Outros sinais clínicos foram anemia, melena, emaciação e redução no ganho de peso. Foram colhidas amostras de sangue de 16 animais, dos quais seis apresentavam sintomas da intoxicação e dez apresentavam-se aparentemente sadios. Destes 16 animais, um apresentou leucopenia e severa anemia; outro animal apresentou leucocitose; três suínos estavam levemente anêmicos e onze animais exibiam hemogramas normais. Com o soro dos 10 animais aparentemente sadios foram realizadas as seguintes provas bioquímicas: uréia nitrogenada sanguínea, fosfatase alcalina, transaminase glutâmica oxalacética - TGO (AST) e transaminase glutâmica pirúvica - TGP (ALT). Foi encontrado um pequeno aumento na atividade média da fosfatase alcalina, TGO (AST) e TGP (ALT), quando comparada à atividade dessas enzimas no soro de suínos que não receberam ração contaminada com sementes de $C$. spectabilis. Após o consumo da ração ocorreram mortes durante as 16 semanas de observação, entretanto a maioria destas ocorreu entre a $8^{\mathrm{a}}$ e $12^{\mathrm{a}}$ semana. Os efeitos tóxicos das sementes foram evidenciados 5 meses após a remoção destas da dieta. Os principais achados patológicos foram úlceras gástricas, hemoperitônio, atrofia e fibrose hepáticas, fibrose renal com cistos glomerulares e pneumonia proliferativa intersticial. Le- 
sões microscópicas de maior valor diagnóstico foram hipertrofia de hepatócitos e de células epiteliais dos túbulos contorcidos renais, com cariomegalia. A severidade dos efeitos causados pela intoxicação por crotalária foi grandemente influenciada pela idade dos suínos. Leitões desmamados um pouco antes de receberem ração contaminada foram mais severamente afetados e apresentaram taxa de mortalidade próxima a $80 \%$, enquanto que suínos com peso próximo ao do abate $(100 \mathrm{~kg})$ tiveram uma mortalidade de $8 \%$ e não houve morte entre as fêmeas.

No Brasil foram realizados experimentos com espécies de Crotalaria somente em bovinos. Tokarnia \& Döbereiner (1982) administraram, por via oral, partes aéreas de Crotalaria mucronata a 21 bovinos. Os achados de necropsia em dois bovinos que ingeriram 60 e $80 \mathrm{~g} / \mathrm{kg}$, foram negativos, e no animal que ingeriu $25 \mathrm{~g} / \mathrm{kg}$ foram observados hidrotórax e edema pulmonar acentuados. Os exames histopatológicos não reveleram alterações consistentes. A partir dos resultados deste trabalho, conclui-se que a toxicidade de $C$. mucronata foi relativamente baixa para bovinos. Tokarnia \& Döbereiner (1983) administraram as partes aéreas de Crotalaria anagyroides, por via oral, a seis bovinos jovens desmamados. Os resultados deste trabalho demonstraram que a planta foi tóxica para essa espécie animal. $O$ achado de necropsia mais importante foi cirrose hepática. Os achados histopatológicos mais importantes foram presença de tecido colágeno, proliferação de fibroblastos e das células epiteliais das vias biliares, megalocitose e a presença de nódulos de regeneração no fígado; em dois animais foi constatada degeneração esponjosa no sistema nervoso central.

O propósito do presente trabalho foi pesquisar, nas condições climáticas e ambientais do Brasil, a toxicidade das sementes de Crotalaria spectabilis para suínos, estudando-se a sintomatologia e a evolução da intoxicação, bem como a presença de lesões macro e microscópicas em órgãos internos de suínos submetidos ao tratamento experimental com estas sementes.

\section{MATERIAL E MÉTODOS}

Foram utilizados 24 suínos mestiços (Landrace x Large White) com idade média de 35 dias. Esses animais receberam ração basal contendo diferentes concentrações de sementes de Crotalaria spectabilis, durante 90 dias. Os tratamentos experimentais foram:

$\mathrm{T}_{1}$ : ração basal, sem sementes de $C$. spectabilis,

$\mathrm{T}_{2}$ : ração basal contendo $0,2 \%$ de sementes de $C$. spectabilis,

$\mathrm{T}_{3}$ : ração basal contendo $0,4 \%$ de sementes de $C$. spectabilis,

$\mathrm{T}_{4}$ : ração basal contendo $0,6 \%$ de sementes de $C$. spectabilis.

As rações basais foram formuladas de forma a atenderem às exigências dos animais nas diferentes fases estudadas, de acordo com o National Research Council (1988).

Os animais que morreram durante o período experimental foram necropsiados logo após a morte. Os remanescentes, que não morreram durante este período, foram sacrificados no último dia do experimento para realização de necropsia.

Durante a necropsia, foram colhidos fragmentos do fígado, rim, pulmão e estômago. Esse material foi fixado em solução de formol tamponado com fosfato, $\mathrm{pH}$ 7,0, por 24 horas. Em seguida, os fragmentos foram desidratados, diafanizados e incluídos em parafina para o preparo de secções de $5 \mathrm{~mm}$ de espessura que foram coradas pelos métodos hematoxilina-eosina (HE), tricrômico de Masson e ácido periódico-Schiff (PAS). Os cortes foram examinados à microscopia de luz.

\section{RESULTADOS}

A partir da $4^{\text {a }}$ semana do experimento, observou-se diminuição no consumo de ração contaminada e no ganho de peso dos suínos intoxicados. Por volta da $6^{\mathrm{a}}$ semana, estes animais começaram a apresentar edemas subcutâneos, principalmente nos membros, na face e no pescoço; mucosas oral e ocular pálidas; cerdas eriçadas; caquexia e apatia. Estes sintomas persistiram até a morte dos suínos, e foram mais acentuados nos animais dos tratamentos 3 e 4, que ingeriram ração com respectivamente, 0,4 e $0,6 \%$ de sementes de Crotalaria spectabilis. Além destes sintomas, dois suínos do tratamento 3 e um do tratamento 2 apresentaram, no último mês de experimento, gastroenterite hemorrágica, seguida pela morte, após um período máximo de 48 horas. Os suínos começaram a morrer a partir da $7^{\mathrm{a}}$ semana de experimento, e a maioria das mortes ocorreu entre a $10^{\mathrm{a}}$ e $13^{\mathrm{a}}$ semana (última semana). Quanto às taxas de mortalidade, ao final do período experimental (90 dias), observou-se $100 \%$ no tratamento 4 (6 animais), 33\% no tratamento 3 (2 animais) e 17\% no tratamento 2 (1 animal).

A incidência dos principais achados de necropsia nos animais que morreram no transcorrer do período experimental e daqueles sacrificados ao final do mesmo, constam no Quadro 1. A anemia caracterizou-se pela presença de mucosas aparentes pálidas. Animais com ascite e/ou hidropericárdio apresentaram acúmulo de líquido, com características de transudato, respectivamente, na cavidade abdominal e/ou saco pericárdico. A gastroenterite hemorrágica foi caracterizada pela presença de líquido sanguinolento e de coloração escura no interior do estômago e dos intestinos. 0 edema subcutâneo gelatinoso e de coloração levemente amarelada ocorreu principalmente na região abdominal, nos membros posteriores e na cabeça. $O$ edema observado na base do coração era gelatinoso e de coloração amarelada. O edema mesentérico também era gelatinoso e apresentava coloração levemente amarelada. $\mathrm{O}$ edema da parede gástrica era gelatinoso, levemente amarelado e estava localizado na submucosa e serosa do estômago, principalmente na região da curvatura maior.

A incidência das lesões microscópicas que ocorreram com maior frequência no fígado de suínos experimentalmente intoxicados com sementes de $C$. spectabilis consta no Quadro 2. A esteatose caracterizou-se pela presença de vacúolos bem delimitados e de dimensões variáveis no citoplasma dos hepatócitos. Na tumefação celular (Fig. 1), os hepatócitos estavam como que amontoados, com citoplasma de aspecto diluído, disperso ou mesmo indistinto. A fibrose (Fig. 2) ocorreu, principalmente, no espaço porta, na zona entre os lóbulos hepáticos e na cápsula. Nessa lesão observou-se grande quantidade de fibras colágenas de pobre celularidade. Na 
Quadro 1. Principais achados de necropsia em suínos submetidos à intoxicação por diferentes concentrações de sementes de Crotalaria spectabilis na ração

\begin{tabular}{|c|c|c|c|c|c|c|c|c|c|}
\hline Tratamento & $\begin{array}{c}\text { Animal } \\
n^{\circ}\end{array}$ & Anemia & Ascite & Hidropericárdio & $\begin{array}{c}\text { Edema } \\
\text { subcutâneo }\end{array}$ & $\begin{array}{l}\text { Edema na } \\
\text { base do } \\
\text { coração }\end{array}$ & $\begin{array}{l}\text { Edema de } \\
\text { mesentério }\end{array}$ & $\begin{array}{c}\text { Edema de } \\
\text { parede } \\
\text { gástrica }\end{array}$ & $\begin{array}{l}\text { Gastroenterite } \\
\text { hemorrágica }\end{array}$ \\
\hline Tratamento 2 & 04 & $+++^{a}$ & - & ++ & - & - & - & - & +++ \\
\hline $0,2 \%$ de & 09 & - & - & - & - & - & - & ++ & - \\
\hline \multirow[t]{4}{*}{ sementes } & 10 & - & - & - & - & - & - & - & - \\
\hline & 14 & - & - & ++ & - & + & - & - & - \\
\hline & 23 & - & + & ++ & - & ++ & - & - & - \\
\hline & 26 & - & - & + & - & - & - & - & - \\
\hline Tratamento 3 & 01 & +++ & - & ++ & - & + & - & - & +++ \\
\hline $0,4 \%$ de & 03 & - & + & ++ & ++ & ++ & - & - & - \\
\hline \multirow{4}{*}{ sementes } & 12 & +++ & - & ++ & - & + & - & - & ++ \\
\hline & 13 & - & - & ++ & - & - & - & - & - \\
\hline & 18 & - & + & - & - & + & - & - & - \\
\hline & 19 & - & + & + & - & ++ & - & - & - \\
\hline Tratamento 4 & 06 & +++ & ++ & ++ & +++ & ++ & +++ & ++ & - \\
\hline $0,6 \%$ de & 07 & ++ & - & ++ & +++ & ++ & ++ & ++ & - \\
\hline \multirow[t]{4}{*}{ sementes } & 15 & ++ & ++ & ++ & ++ & ++ & ++ & ++ & - \\
\hline & 16 & - & - & ++ & ++ & ++ & - & - & - \\
\hline & 20 & - & + & ++ & +++ & ++ & ++ & ++ & - \\
\hline & 21 & ++ & ++ & ++ & +++ & ++ & - & - & - \\
\hline
\end{tabular}

a +++ Lesão acentuada, ++ moderada, + leve, - ausente.

Quadro 2. Principais alterações histológicas observadas no fígado de suínos submetidos à intoxicação por diferentes concentrações de sementes de $C$. spectabilis na ração

\begin{tabular}{|c|c|c|c|c|c|c|c|c|c|}
\hline Tratamento & $\begin{array}{c}\text { Animal } \\
n^{0}\end{array}$ & Esteatose & $\begin{array}{c}\text { Tumefação } \\
\text { celular }\end{array}$ & Fibrose & $\begin{array}{c}\text { Hepatite } \\
\text { portal } \\
\text { crônica }\end{array}$ & $\begin{array}{l}\text { Hepatite } \\
\text { crônica }\end{array}$ & $\begin{array}{c}\text { Hepatite } \\
\text { intersticial } \\
\text { crônica focal }\end{array}$ & $\begin{array}{l}\text { Megalo- } \\
\text { citose }\end{array}$ & $\begin{array}{c}\text { Proliferação } \\
\text { de ductos } \\
\text { biliares }\end{array}$ \\
\hline Tratamento 2 & 04 & $-{ }^{a}$ & ++ & ++ & - & - & ++ & ++ & ++ \\
\hline $0,2 \%$ de & 09 & ++ & ++ & ++ & - & ++ & - & ++ & ++ \\
\hline \multirow[t]{4}{*}{ sementes } & 10 & ++ & - & ++ & - & - & ++ & ++ & ++ \\
\hline & 14 & ++ & - & ++ & - & ++ & - & ++ & ++ \\
\hline & 23 & - & +++ & ++ & - & ++ & - & ++ & ++ \\
\hline & 26 & - & - & ++ & - & - & ++ & ++ & ++ \\
\hline Tratamento 3 & 01 & ++ & - & +++ & - & - & - & ++ & +++ \\
\hline $0,4 \%$ de & 03 & ++ & - & +++ & - & ++ & - & ++ & +++ \\
\hline \multirow[t]{4}{*}{ sementes } & 12 & ++ & - & ++ & +++ & - & - & ++ & ++ \\
\hline & 13 & - & ++ & ++ & - & - & - & ++ & ++ \\
\hline & 18 & - & ++ & + & - & - & - & ++ & + \\
\hline & 19 & - & ++ & + & - & - & - & ++ & + \\
\hline Tratamento 04 & 06 & +++ & - & ++ & - & - & - & ++ & ++ \\
\hline $0,6 \%$ de & 07 & ++ & - & ++ & - & - & - & ++ & ++ \\
\hline \multirow[t]{4}{*}{ sementes } & 15 & ++ & - & ++ & - & - & - & ++ & ++ \\
\hline & 16 & ++ & - & +++ & - & - & - & ++ & +++ \\
\hline & 20 & +++ & - & +++ & - & - & - & ++ & +++ \\
\hline & 21 & ++ & ++ & ++ & - & - & - & ++ & ++ \\
\hline
\end{tabular}

a +++ Lesão acentuada, ++ moderada, + leve, - ausente.

hepatite portal crônica notou-se a presença de infiltrado inflamatório predominantemente mononuclear nos espaços porta; já na hepatite intersticial crônica focal esse infiltrado permeava algumas zonas do interstício, e na hepatite crônica observou-se envolvimento tanto do sistema porta como do tecido intersticial hepático. Observou-se a presença de vários eosinófilos nesse infiltrado inflamatório hepático. A megalocitose (Fig. 1) caracterizou-se pela presença de megalócitos, que são hepatócitos apresentando gigantismo nuclear e citoplasmático. Na proliferação de ductos biliares, observaram-se vários ductos biliares no interior dos espaços porta.

A incidência das principais lesões microscópicas observadas nos rins dos animais experimentais consta no Quadro 3. A esteatose caracterizou-se pela presença de vacúolos bem delimitados e de tamanho variável no citoplasma das células epiteliais tubulares. Na nefrite intersticial crônica difusa (Fig. 3) observou-se infiltrado inflamatório predominante- 


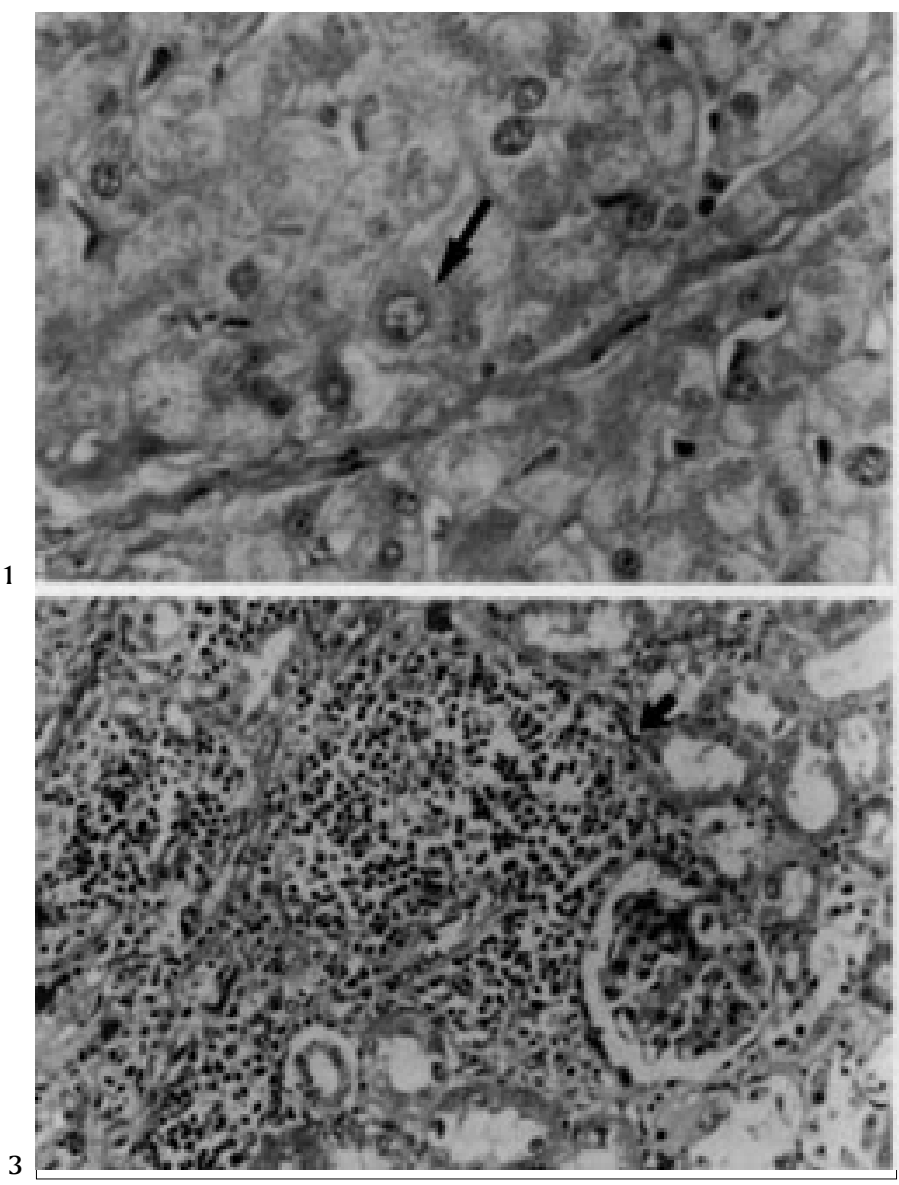

Fig.1. Tumefação dos hepatócitos e megalocitose (seta) em suíno experimentalmente intoxicado por $0,2 \%$ de sementes de Crotalaria spectabilis, aos 90 dias de experimento. HE, obj. 40.

Fig. 3. Intenso infiltrado inflamatório mononuclear no interstício renal (seta) de suíno experimentalmente intoxicado por 0,6\% de sementes de Crotalaria spectabilis, aos 88 dias de experimento. HE, obj. 20.
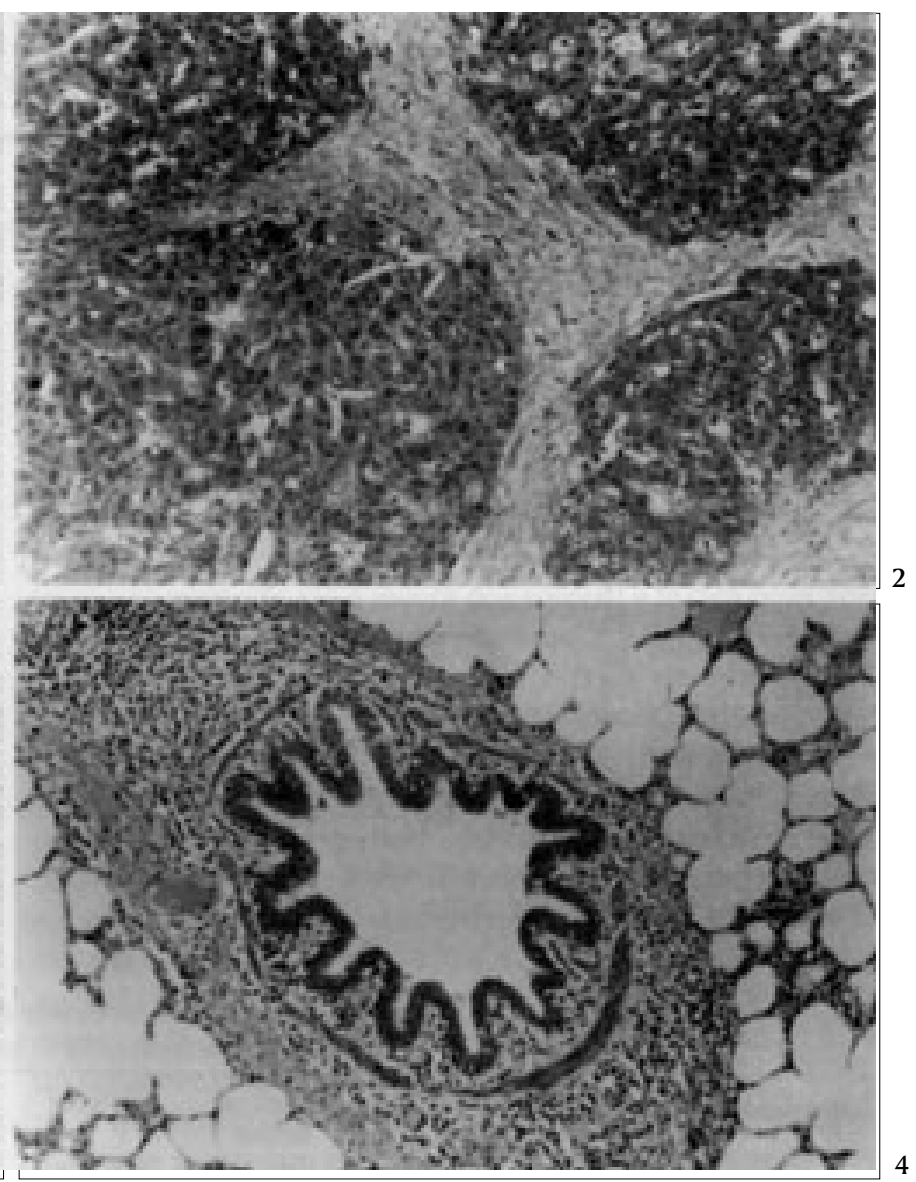

Fig. 2. Intensa fibrose entre os lóbulos hepáticos de suíno experimentalmente intoxicado por $0,4 \%$ de sementes de Crotalaria spectabilis, aos 90 dias de experimento. Tricrômico de Masson, obj. 10.

Fig. 4. Infiltrado inflamatório mononuclear peribronquial em suíno experimentalmente intoxicado por $0,4 \%$ de sementes de Crotalaria spectabilis, aos 90 dias de experimento. HE, obj. 10.

Quadro 3. Principais alterações histológicas observadas nos rins de suínos submetidos à intoxicação por diferentes concentrações de sementes de $C$. spectabilis na ração

\begin{tabular}{|c|c|c|c|c|c|}
\hline Tratamento & $\begin{array}{c}\text { Animal } \\
\mathbf{n}^{\circ}\end{array}$ & Esteaose & $\begin{array}{l}\text { Nefrite intersticial } \\
\text { crônica difusa }\end{array}$ & $\begin{array}{l}\text { Nefrite intersticial } \\
\text { crônica focal }\end{array}$ & Megalocitose \\
\hline Tratamento 2 & 04 & $\mathrm{a}$ & ++ & - & ++ \\
\hline $0,2 \%$ de & 09 & ++ & ++ & - & ++ \\
\hline \multirow[t]{4}{*}{ sementes } & 10 & +++ & - & ++ & + \\
\hline & 14 & +++ & - & +++ & +++ \\
\hline & 23 & - & - & + & ++ \\
\hline & 26 & - & ++ & - & ++ \\
\hline Tratamento 3 & 01 & - & - & + & ++ \\
\hline $0,4 \%$ de & 03 & - & - & + & ++ \\
\hline \multirow[t]{4}{*}{ sementes } & 12 & ++ & +++ & - & ++ \\
\hline & 13 & - & ++ & - & ++ \\
\hline & 18 & - & ++ & - & + \\
\hline & 19 & ++ & ++ & - & ++ \\
\hline Tratamento 4 & 06 & - & - & - & + \\
\hline $0,6 \%$ de & 07 & - & - & + & + \\
\hline \multirow[t]{4}{*}{ sementes } & 15 & - & - & ++ & + \\
\hline & 16 & - & ++ & - & ++ \\
\hline & 20 & ++ & ++ & - & ++ \\
\hline & 21 & - & - & - & + \\
\hline
\end{tabular}

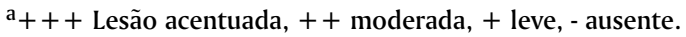


Quadro 4. Principais alterações histológicas observadas nos pulmões de suínos submetidos à intoxicação por diferentes concentrações de sementes de $C$. spectabilis na ração

\begin{tabular}{|c|c|c|c|c|c|}
\hline Tratamento & $\begin{array}{c}\text { Animal } \\
n^{0}\end{array}$ & $\begin{array}{l}\text { Broncopneu- } \\
\text { monia crônica }\end{array}$ & $\begin{array}{l}\text { Bronquite } \\
\text { crônica }\end{array}$ & $\begin{array}{l}\text { Enfisema } \\
\text { pulmonar }\end{array}$ & $\begin{array}{c}\text { Edema } \\
\text { pulmonar }\end{array}$ \\
\hline Tratamento 2 & 04 & $-a$ & ++ & + & - \\
\hline $0,2 \%$ de & 09 & +++ & - & ++ & - \\
\hline \multirow[t]{4}{*}{ sementes } & 10 & +++ & - & ++ & ++ \\
\hline & 14 & - & - & + & ++ \\
\hline & 23 & - & + & ++ & - \\
\hline & 26 & - & ++ & ++ & - \\
\hline Tratamento 3 & 01 & ++ & - & ++ & ++ \\
\hline $0,4 \%$ de & 03 & ++ & - & - & +++ \\
\hline \multirow[t]{4}{*}{ sementes } & 12 & - & ++ & ++ & ++ \\
\hline & 13 & ++ & - & ++ & - \\
\hline & 18 & - & ++ & ++ & ++ \\
\hline & 19 & - & ++ & ++ & - \\
\hline Tratamento 4 & 06 & ++ & - & ++ & - \\
\hline $0,6 \%$ de & 07 & ++ & - & ++ & - \\
\hline \multirow[t]{4}{*}{ sementes } & 15 & - & - & ++ & - \\
\hline & 16 & ++ & - & - & ++ \\
\hline & 20 & - & + & ++ & ++ \\
\hline & 21 & - & - & - & - \\
\hline
\end{tabular}

a +++ Lesão acentuada, ++ moderada, + leve, - ausente.

Quadro 5. Principais alterações histológicas observadas no estômago de suínos submetidos à intoxicação por diferentes concentrações de sementes de $C$. spectabilis na ração

\begin{tabular}{ccccc}
\hline Tratamento & Animal & $\begin{array}{c}\text { Gastrite } \\
\text { crônica }\end{array}$ & $\begin{array}{c}\text { Gastrite } \\
\text { eosinofilica }\end{array}$ & $\begin{array}{c}\text { Gastrite } \\
\text { gástrica }\end{array}$ \\
\hline Tratamento 2 & 04 & $+++^{\mathrm{a}}$ & - & ++ \\
$0,2 \%$ de & 09 & - & - & - \\
sementes & 10 & - & ++ & - \\
& 14 & - & +++ & +++ \\
& 23 & - & +++ & + \\
Tratamento 3 & 26 & - & - & ++ \\
$0,4 \%$ de & 01 & +++ & - & ++ \\
sementes & 03 & +++ & - & - \\
& 12 & ++ & - & - \\
& 13 & - & - & ++ \\
Tratamento 4 & 18 & - & - & ++ \\
$0,6 \%$ de & 19 & +++ & - & - \\
sementes & 06 & ++ & - & - \\
& 07 & +++ & +++ & - \\
& 15 & ++ & -++ & ++
\end{tabular}

a +++ Lesão acentuada, ++ moderada, + leve, - ausente.

mente mononuclear permeando difusamente o interstício renal; já na nefrite intersticial crônica focal, esse infiltrado estava presente em algumas zonas do interstício renal. A megalocitose caracterizou-se por gigantismo nuclear e citoplasmático das células epiteliais tubulares.

As lesões microscópicas mais comuns nos pulmões de suínos intoxicados com sementes de $C$. spectabilis estão expostas no Quadro 4. De uma maneira geral, na broncopneumonia crônica notou-se infiltração inflamatória predominantemente mononuclear ao redor de brônquios e bronquíolos e no interstício pulmonar; nesse infiltrado intersticial foram observados pequenos focos de neutrófilos.
A bronquite crônica (Fig. 4) caracterizou-se pela presença de infiltrado inflamatório predominantemente mononuclear peribronquial e peribronquiolar. Nos animais 9 e 10 foram observadas células gigantes no infiltrado inflamatório intersticial; ressalta-se que fragmentos pulmonares desses animais foram submetidos à coloração Ziehl-Neelsen e não foram encontrados bacilos da tuberculose. $\mathrm{O}$ edema pulmonar caracterizou-se, microscopicamente, pela presença de material levemente amarelado no interstício e/ou alvéolos pulmonares. No enfisema pulmonar observou-se aumento anormal dos alvéolos e destruição das suas paredes.

As lesões que ocorreram com maior frequência durante $o$ exame microscópico de fragmentos do estômago dos animais experimentais estão relacionadas no Quadro 5. A gastrite crônica caracterizou-se pela infiltração difusa de células inflamatórias predominantemente mononucleares, principalmente na mucosa e submucosa gástrica. Na gastrite eosinofílica observou-se um infiltrado inflamatório predominantemente por eosinófilos localizados sobretudo nas camadas mucosa e submucosa. A úlcera, localizada na região esofágica do estômago, caracterizou-se por apresentar abaixo da zona de necrose restos celulares, neutrófilos e uma grande área de reparação, com proliferação de tecido conjuntivo, proliferação de fibroblastos, neovasculariza-ção e presença de intenso infiltrado de células mono e polimorfonucleares.

0 exame dos órgãos internos dos animais do grupo controle (Tratamento 1) não revelou alterações macro e/ou microscópicas.

\section{DISCUSSÃO E CONCLUSÕES}

$O$ presente trabalho demonstrou que rações contaminadas com diferentes concentrações de sementes de $C$. spectabilis $\left(\mathrm{T}_{2}: 0,2, \mathrm{~T}_{3}: 0,4\right.$ e $\mathrm{T}_{4}: 0,6 \%$ ) foram altamente tóxicas para suínos.Os sintomas observados, em suínos que receberam 
rações contaminadas por $0,2,0,4$ e $0,6 \%$ de sementes de Crotalaria spectabilis, foram semelhantes aos anteriormente descritos por Emmel et. al. (1935), Emmel (1943) e Peckham et al. (1974), em suínos intoxicados pela mesma planta.

\section{REFERÊNCIAS}

Bull L.B. 1955. The histological evidence of liver damage from pyrrolizidine alkaloids: megalocytosis of the liver cells and inclusion globules. Aust. Vet. J. 18:33-40.

Burrows G.E. 1991. The identification of hepatotoxic pyrrolizidine alkaloid exposure in horses by the demonstration of sulphur-bound pyrrolic metabolites on their hemoglobin. Vet. Hum. Toxicol. 33(3):286-287.

Carstens L.A. \& Allen J.R. 1970. Arterial degeneration and glomerular hyalinization in the kidney of monocrotaline-intoxicated rats. Am. J. Pathol. 60:75-90.

Cheeke P.R. \& Garman G.R. 1974. Influence of dietary protein and sulfur amino acid levels on the toxicity of Senecio jacobaea (Tansy Ragwort) to rats. Nutr. Rep. Int. 9:197.

Cheeke P.R. \& Shull L.R. 1985. Natural toxicants in feeds and poisonous plants. AVI Publishing, Westport.

Emmel M.W. 1943. Livestock poisoning by Crotalaria spectabilis. Vet. Med. 255-257.

Emmel M.W., Sanders D.A. \& Henley W.W. 1935. Crotalaria spectabilis roth seed poisoning in swine. J. Am. Vet. Med. Assoc. 86:43-54.

Figueredo M.L.A., Rodríguez J. \& Alfonso H.A. 1987. Patologia de la intoxicacion experimental aguda por Crotalaria retusa y $C$. spectabilis em pollos. Revta Cubana Cienc. Vet. 18(1/2):63-71.

Hayashi Y. \& Lalich J.J. 1967. Renal and pulmonary alterations induced in rats by a single injection of monocrotaline. Proc. Soc. Exp. Biol. Med. 124:392396.

Johnson A.E, Molyneux R.J. \& Merril G.B. 1985. Chemistry of toxic range plants: variation in pyrrolizidine alkaloid content of Senecio, Amsinckia and Crotalaria species. J. Agric. Food. Chem. 33(1):50-55.

Jubb K.V.F., Kennedy P.C. \& Palmer N. 1993. Pathology of Domestic Animals. 4th ed. Academic Press, New York, p. 392-395.

Mattocks A.R. 1972. Acute hepatotoxicity and pyrrolic metabolites in rats dosed with pyrrolizidine alkaloids. Chem. Biol. Inter. 5:227-242. (Citado por Burrows 1991)

Mattocks A.R. 1986. Chemistry and Toxicology of Pyrrolizidine Alkaloids. Academic Press, Orlando. 393 p.

McGrath J.P.M., Duncan J.R. \& Munnell J.F. 1975. Crotalaria spectabilis toxicity in swine: characterization of the renal glomerular lesion. J. Comp. Pathol. 85:185-194.

Miranda C.L., Cheeke P.R., Schmitz J.A. \& Buhler D.R. 1980. Toxicity of Senecio jacobaea (Tansy Ragwort) in rats. Toxicol. Appl. Pharmacol. 56:432.

National Research Council. 1988. Nutrient requirements of swine. 9th ed. National Academy Press, Washington. 93 p.

Neal W.M., Rusoff, L.L. \& Ahmann, C.F. 1935. The isolation and some properties of an alkaloid from Crotalaria spectabilis roth. Am. Chem. Soc. J. 572:25602561.

Peckham J.C., Sangster L.T. \& Jones Junior O.H. 1974. Crotalaria spectabilis poisoning in swine. J. Am. Vet. Med. Assoc. 165(7):633-638.

Piercy P.L. \& Rusoff L.L. 1946. Crotalaria spectabilis poisoning in Louisiana livestock. J. Am. Vet. Med. Assoc. 108(1946):69-72.

Sangster L.T. 1972. A pathologic study of chronic Crotalaria spectabilis intoxication in swine. M.Sc. thesis, University of Georgia, Athenas. 60p.

Thomson R.G. 1990. Patologia Veterinária Especial. Manole, São Paulo, p. 291.

Tokarnia C.H. \& Döbereiner J. 1982. Intoxicação experimental por Crotalaria mucronata (Leg. Papilionoideae) em bovinos. Pesq. Vet. Bras. 2(2):77-85.

Tokarnia C.H. \& Döbereiner J. 1983. Intoxicação experimental por Crotalaria anagyroides (Leg. Papilionoideae) em bovinos. Pesq. Vet. Bras. 3(4):115-123. 